\title{
La critique littéraire scientifique, surgeon de la linguistique générale
}

Une illustration à partir de trois inédits. Critiques d'un poème de Stéphane Mallarmé

\section{Gérard Zamioune}

\section{(2) OpenEdition} Journals

Édition électronique

URL : http://journals.openedition.org/rlv/1219

DOI : 10.4000/rlv. 1219

ISSN : 1958-9239

Éditeur

Presses universitaires de Vincennes

\section{Édition imprimée}

Date de publication : 1 mai 1999

Pagination : 179-182

ISSN : 0986-6124

Référence électronique

Gérard Zamioune, «La critique littéraire scientifique, surgeon de la linguistique générale », Recherches linguistiques de Vincennes [En ligne], 28 | 1999, mis en ligne le 09 septembre 2005, consulté le 06 mai 2019. URL : http://journals.openedition.org/rlv/1219; DOI : 10.4000/rlv.1219 


\section{Rubrique patalinguistique}

\section{Gérard ZAMIOUNE}

\section{LA CRITIQUE LITTÉRAIRE SCIENTIFIQUE, SURGEON DE LA LINGUISTIQUE GÉNÉRALE UNE ILLUSTRATION À PARTIR DE TROIS INÉDITS Critiques d'un poème de Stéphane Mallarmé}

On entend parfois dire que la critique littéraire scientifique, telle le bébé en bambinette, a franchi le seuil de son parc et que l'enfant, qui maintenant a grandi, toise avec condescendance celle qui l'a nourrie de ses concepts, à savoir la linguistique générale. À cette conception de l'émancipation, campant fermement sur mes habituelles positions et, une fois de plus, preuves à l'appui, je répondrai en utilisant la métaphore suivante : la critique littéraire comme science est à la linguistique fondamentale ce que l'ordinateur est à celui qui met la prise de courant.

J'illustrerai mon propos à partir de trois commentaires critiques inédits du poème À la nue de Stéphane Mallarmé.

Ainsi ferai-je d'une pierre deux coups puisque je tempérerai l'inquiétude d'Anna Faure qui, en authentique pythonisse, voilà déjà deux ans, me glissait : «L'année 1998 sera l'année du centenaire de la mort de Mallarmé ou ne sera pas.» Il eût été inconvenant, en effet, que le cru 1998 de Recherches linguistiques de Vincennes ne s'associât pas, à sa manière, aux cérémonies commémoratives célébrant la mémoire du Poète.

À quelque chose, malheur est bon; la mort récente de H. Bustos Domecq ${ }^{1}$, légataire universel de Pierre Ménard, a permis au monde littéraire, éberlué, de découvrir un volet totalement méconnu du grand homme : son œuvre critique, d'une considérable ampleur.

Les esprits superficiels prétendront qu'entre Pierre Ménard, l'écrivain ${ }^{2}$ et Pierre Ménard, le critique, la différence, sur le papier, paraît bien mince. Rien à voir, pourtant : comment, en effet, assimiler le torrent verbal du colossal auteur du Quichotte qui « incorpore »d'un seul tenant ses œuvres romanesques à la procrastination du critique qui, ses brouillons en portent l'éloquent témoignage, couvre ses épreuves de ratures, de surcharges et de rectifications? 
Non, la vocation critique de notre érudit nîmois a enfanté dans la douleur. Elle n'en a, de ce fait, que plus de prix. Jugeons sur pièces notre dossier : regroupés dans une boîte en carton portant l'étiquette : Commentaire critique $d u$ poème À la nue de Stéphane Mallarmé, voici 7 cahiers d'écoliers de cinquante pages chacun, entièrement bleuis par la fine écriture du maître.

Faute de place je me contenterai de fournir des exemples tirés du premier cahier ; Pierre Ménard l'inaugure ainsi : "Le poème À la nue de Stéphane Mallarmé, écrit en 1895... », dans cet extrait, à l'exception du titre À la nue, tout le reste, biffé, fait l'objet de commentaires et renvois dans la marge tels que : " inutilité de dire ce que chacun est à même de vérifier dans toutes les histoires de la Poésie »... puis, par exemple, quinze pages plus loin, on peut lire, en commentaire du premier vers : «tu : s'agit-il du pronom deuxième personne $d u$ singulier en fonction sujet? Ou bien alors du participe passé du verbe "taire"? Peut-être s'agit-il de la note UTqui correspond à la fréquence du son émis par la trompe du quatrième vers, erreur que le poète, alors fatigué, n'a pas pris soin de corriger, décidant, par cette bifurcation plaisante, du sort rimique de l'ensemble du poème ?...» Les questions, impitoyablement biffées se succèdent ainsi sur trois pleines pages, ne laissant émerger du gâchis que le mot «tu » et les renvois dans la marge comme « À quoi bon toutes ces questions si c'est pour les laisser sans réponse. Tant pis, il faut sacrifier...».

Patience, patience, cher lecteur... car, une fois évacués tous les éléments barrés d'un trait de plume, ainsi que les superfétatoires commentaires de la marge, ne subsiste alors, rescapé de cet océan de repentirs, que le motif du tapis, le dessin de l'Indien caché dans la forêt tropicale, le filigrane de la pensée critique de Pierre Ménard, c'est-à-dire le texte suivant, composé des éléments intouchés mis bout à bout, privés de leurs guillemets, conservant leurs majuscules, et suivis de la signature de Pierre Ménard, laquelle atteste, au bas de la dernière page du dernier cahier, l'authenticité du travail critique :

À la nue... À la nue accablante tu Basse de basalte et de laves À même les échos esclaves Par une trompe sans vertu Quel sépulcral naufrage (tu Le sais, écume, mais y baves) Suprême une entre les épaves Abolit le mât dévêtu Ou cela que furibond faute De quelque perdition haute Tout l'abîme vain éployé Dans le si blanc cheveu qui traîne Avarement aura noyé Le flanc enfant d'une sirène.

Pierre Ménard, Nîmes, 1932-35.

Certains, sans doute par pure rancœur, m'ont fait remarquer que les scrupules qui rongent Pierre Ménard n'ont pu avoir, faute d'être révélés à temps, un effet préventif sur les théoriciens de l'analyse de textes. Me situant au dessus de la mêlée, je prierai plus sérieusement le lecteur de revenir à la date de composition : les années 30 et leur antimentalisme ; le corpus, tout le corpus et rien que le corpus. Once « À la nue... », always « À la nue... ». Même lorsque l'on s'appelle Pierre Ménard et que l'on s'estime affranchi du paradigme ambiant, la science est là, qui tend ses filets épistémiques aux applicateurs. 
Autres temps, autres mœurs. Les sulfureuses années 70 ont laissé dans le siècle un parfum d'indécence. Il était annoncé trois textes inédits: je l'avoue, pour ce second texte, publié en 1972, c'est inexact. Mais, à ma décharge, qui se souvient encore du numéro zéro de la très éphémère revue Poetectomie (tout un programme) concoctée dans la haine par une bande de dandys révoltés ? Et, parmi eux, Louis Morvandiau. Peut-on imaginer que l'actuelle poutre maîtresse des Foyers de Poëtologie, au sous-titre si reposant «La poésie (comme) chez soi », s'était gavée du lait amer du terrorisme littéraire ? Certes, à une époque où, selon une célèbre prosopopée les bombes atomiques étaient animées d'intentions impérialistes (l'Américaine, la Russe) ou libératrices (la Chinoise) ${ }^{3}$, le jeune Morvandiau avait, reconnaissons-le, bien des excuses.

Ayant ravivé quelques souvenirs qui ne feront pas plaisir à tout le monde, j'attends, résigné mais serein, l'immanquable procès, et j'en viens, séance tenante, aux faits. Dans un avant-propos en forme de réquisitoire, notre Fouquier-Tinville de la littérature s'en prend globalement à la poésie, art précieux par excellence, et aux poètes, thuriféraires de l'ordre bourgeois. Miraculeusement épargné par un tel jeu de massacre, Stéphane Mallarmé s'en sort plutôt bien : en effet, nous dit Louis Morvandiau, si la forme de sa poésie est affligeante de clichés idéologiques, elle n'en recèle pas moins un contenu masqué et subversif. Et de nous avouer que, pendant que ses camarades de collège s'usaient à la lecture de revues pornographiques, lui, Morvandiau, passait ses nuits d'adolescent à feuilleter d'une main fébrile les recueils de poèmes de Mallarmé. Seulement, pour accéder au contenu caché des poèmes, il convient de leur faire subir la bonne vieille prise de judo marxiste. À titre d'exemple, notre jeune auteur nous présente le hishi mata qu'il a réservé au poème À la nue dans lequel, assure-t-il, on ne peut pas ne pas voir mis en scène, selon la formule lacanienne « il n'y a pas de rapport sexuel », l'irréductibilité des sexes et l'insondable mystère de la Femme :

Le grand cri de la jouissance féminine n'aura pu retentir parmi les quelques ahanements bestiaux d'un partenaire forcément médiocre Confirmant cet échec copulatoire un impuissant filet spermatique témoigne de la misérable pendeloque qu'est devenue ce qui fut auparavant si fièrement brandi Mais à jouissance impossible immanente vengeance : l'orifice béant par un colérique engloutissement les rendant inopérantes causera l'égarement des cellules mâles et ne donnera lieu qu'à une chimérique et imaginaire issue.

Je ne me prononcerai pas sur le fait de savoir lequel de l'original ou de sa copie porte plus haut le flambeau de la poésie ; lequel de l'avant ou de l'après chirurgical est le plus esthétique ${ }^{4}$. La question est d'ordre épistémologique: outre l'évidente filiation avec les velléités reconstructrices d'un Schleicher (voir $L a$ brebis et les chevaux), l'appareil technique mis en œuvre consiste bien en une fusion alchimique entre paraphrases harrissiennes d'une part, et règles de réécriture de la théorie standard ${ }^{5}$, de l'autre. 
Last but not least, la talentueuse jeune chercheuse, Kate Alborough, vient d'envoyer, de son Wisconsin natal, un fameux pavé dans la mare. S'inscrivant dans la lignée de ceux qui voient dans À la nue, un haïku préparatoire au Coup de Dés..., elle en assène enfin l'irréfutable preuve. « Trop court », fut la réponse, bien unanime pour être honnête, des éditeurs. Recherches linguistiques de Vincennes a décidé de réparer cette iniquité, et voici donc, dans sa version intégrale, le texte de Kate Alborough précédé de son titre :

À la nue... : un premier jet du Coup de dés

\section{À LANUE $=$ UN ALÉA}

Kate Alborough, Université du Wisconsin

Certains y verront l'annonce que, devenue équative, la critique littéraire est enfin promue au rang de science exacte, scellant ainsi son autonomie. Loin s'en faut : comment ne pas voir, au contraire, et à l'appui de la thèse défendue ici, que, moyennant quelques déplacements paramétriques, se déroule sous nos yeux et comme en temps réel, une application sophistiquée du programme minimaliste chomskyien.

\section{NOTES}

1. Le Président de la Société des Amis de H. Bustos Domecq, Gervasio Montenegro, me prie de faire savoir que celui-ci, qui maîtrisait mal notre langue, n'a fait rien d'autre que de se mettre en conformité avec l'expression testamentaire « ... aux soins jaloux », réinvestie au pied de la lettre.

2. Sur l'écrivain Pierre Ménard, on consultera ce qui s'impose comme biographie de référence : J. L. Borges, «Pierre Ménard, auteur du Quichotte », Fictions, 1957.

3. La Française, telle Charlot, claudiquait, à cheval sur la ligne frontière.

4. Je déconseille vivement la solution paresseuse qui, faisant fi des conditions " atmosphériques » de production, consisterait à court-circuiter l'original en se reportant à l'œuvre critique de Pierre Ménard, présentée ci-dessus.

5. Le lecteur comprendra que le contexte, somme toute scabreux, m'interdit de la qualifier d'étendue. 